\title{
A 16-year-old Girl with Morquio Syndrome: A Case Report
}

\author{
Bhuiyan AKMMR ${ }^{\mathrm{a}}$, Jannat $\mathrm{M}^{\mathrm{b}}$, Sarker MZMc, Islam MT ${ }^{\mathrm{d}}$, Chowdhury AR $^{\mathrm{e}}$
}

\begin{abstract}
Morquio syndrome is a rare autosomal recessive disorder of mucopolysaccharide metabolism, also called mucopolysaccharidosis type IV. We report a case of Morquio syndrome in al6-year-old girl of normal intelligence, who got herself admitted in Bangabandhu Sheikh Mujib Medical University, Dhaka, Bangladesh. The patient had short stature and skeletal deformity and she belonged to a non-consanguineous marriage of her parents. She was diagnosed on the basis of clinical features, typical radiological changes and positive urinary mucopolysaccharide screening test.
\end{abstract}

Key words: Morquio syndrome, Bangladesh, mucopolysaccharidosis

(BIRDEM Med J 2018; 8(3): 266-269)

\section{Introduction}

Morquio syndrome is a rare inherited disorder of mucopolysaccharide metabolism. Among seven different types, Morquio syndrome is type IV mucopolysaccharidosis (Type IV-A and Type IV-B) which caused by deficiency of $\mathrm{N}$-acetylgalactosamine6-sulfatase and â-galactosidase respectively, each resulting in a defective degradation of keratan sulfate. ${ }^{1}$ The internationally estimated incidence of Morquio syndrome covers a wide range of 1 case among 75000 to 250000 in different parts of Europe. ${ }^{2}$ In 1929, Mr. Morquio, a pediatrician in Uruguay and an English radiologist Mr. Brailsford independently and

Author Information

a. Dr. A K M Motiur Rahman Bhuiyan, Associate Professor, Internal Medicine, Bangabandhu Sheikh Mujib Medical University, Dhaka.

b. Dr. Maftahul Jannat, Bangabandhu Sheikh Mujib Medical University, Dhaka.

c. Prof. Md. Zilan Miah Sarker, Professor, Internal Medicine, Bangabandhu Sheikh Mujib Medical University, Dhaka.

d. Dr. Mohammad Tanvir Islam, Associate Professor, Internal Medicine, Bangabandhu Sheikh Mujib Medical University, Dhaka.

e. Dr. Amit Roy Chowdhury, Bangabandhu Sheikh Mujib Medical University, Dhaka.

Address of correspondence: Dr. Mohammad Tanvir Islam, Associate Professor, Internal Medicine, Bangabandhu Sheikh Mujib Medical University, Dhaka. Email: dr.mdtanvirislam@gmail.com,

Received: July 31, 2018

Accepted: August 6, 2018 simultaneously described what is known as MorquioBrailsford syndrome. ${ }^{3,4}$

In children with Morquio syndrome, body cannot breakdown sugar chains called glycosaminoglycan, that helps to build bone, cartilage, eyes, cornea, skin, connective tissue (tendons and ligaments) etc. due to lack or inactivity of lysosomal enzymes. As a result, glycosaminoglycans accumulate in cells, blood, bones and connective tissue and causes damage over time.

\section{Case Report}

A 16-year-old girl got herself admitted in Internal Medicine Department of Bangabandhu Sheikh Mujib Medical University (BSMMU) with growth failure, swelling and deformity of back, low back pain and occasional shortness of breath on exertion for 2 years. She was delivered by normal vaginal delivery at full term and was healthy with average weight. Both antenatal and postnatal periods were uneventful. Her parents were of normal height and there was no history of consanguinity. Her only younger brother had normal growth and development. History did not reveal any familial incidence of similar disorder. The girl had normal growth and development till the age of 5 years after that she did not grow as much as other children of the same age.

General physical examination revealed that the girl looked disproportionately short with short neck and trunk. Limbs were normal in length though they appeared long in relation to the trunk. There were lumbar 
kyphosis and gibbus, mild genu valgus and pectus carinatum. Her pulse was $100 \mathrm{~b} / \mathrm{min}$ with water hammer character, blood pressure was $90 / 60 \mathrm{~mm} \mathrm{Hg}$ and temperature was normal. Anthropometry revealed head circumference $53 \mathrm{~cm}$, height $127 \mathrm{~cm}$, arm span $145 \mathrm{~cm}$, weight $24 \mathrm{~kg}$, body mass index (BMI) $15 \mathrm{~kg} / \mathrm{m}^{2}$. The CDC (Centers for Disease Control and Prevention) growth chart showed height for age and weight for age both were below $5^{\text {th }}$ centile.

There was lumbar gibbus and mild restriction of movement of lumbar spine and hyper mobility of joints. Mild pectus carinatum with reduced chest expansion and an early diastolic murmur in the aortic area was also noted. Ophthalmological examination revealed her vision 6/9 on both eyes and mild corneal clouding was noted on slit lamp biomicroscopy. Fundoscopy showed cherry red macula. Her I.Q. (Intelligence Quotient) and neurological examination was normal.

She had bilateral sensory neural deafness as evidenced on pure tone audiometry. Oral examination showed multiple decayed teeth with over retained tooth pieces of primary teeth. OPG (orthopantomogram) showed decayed teeth.

\section{Radiological features}

Definite flattening of vertebral bodies with central beaking were seen in cervical and lumbar regions with kyphoscoliosis (Figure 1,2). There was mild genu vulgum and ribs were broad and wide (Figure 3,4). Pelvic radiograph showed shallow acetabulum and deformed irregular femoral head with dislocation (Figure 5). Those findings are strongly suggestive of Morquio syndrome.

\section{Laboratory findings}

Her haemoglobin was $12.3 \mathrm{mg} / \mathrm{dl}$, ESR $10 \mathrm{~mm}$ in $1^{\text {st }}$ hour, WBC 7400/cumm with polymorphonuclear leukocyte and intracytoplasmic stipling (Reilly bodies), RBS $5.6 \mathrm{mmol} / \mathrm{L}$, S. calcium $8.2 \mathrm{mg} / \mathrm{dl}$, S. alkaline phosphatase $423 \mathrm{U} / \mathrm{L}$, S. creatinine $4 \mathrm{mg} / \mathrm{dl}$, S. inorganic phosphate $4.9 \mathrm{mg} / \mathrm{dl}$, S. parathyroid hormone $26.5 \mathrm{pg} /$ $\mathrm{ml}$, and vitamin D (25 hydroxy) $8.5 \mathrm{ng} / \mathrm{ml}$ which was below normal range. ECG showed $\mathrm{T}$ inversion in $\mathrm{V}_{1}$ to $\mathrm{V}_{6}$. Echocardiogram showed mild cardiomegaly and aortic regurgitation, ultrasonogram of whole abdomen showed mild hepatomegaly.

Urinary keratan sulfate was $38 \mathrm{mg} / \mathrm{L}$, that was more than normal (control $10 \mathrm{mg} / \mathrm{L}$ ). Direct enzymatic assay was not done due to unavailability of the test in our country.

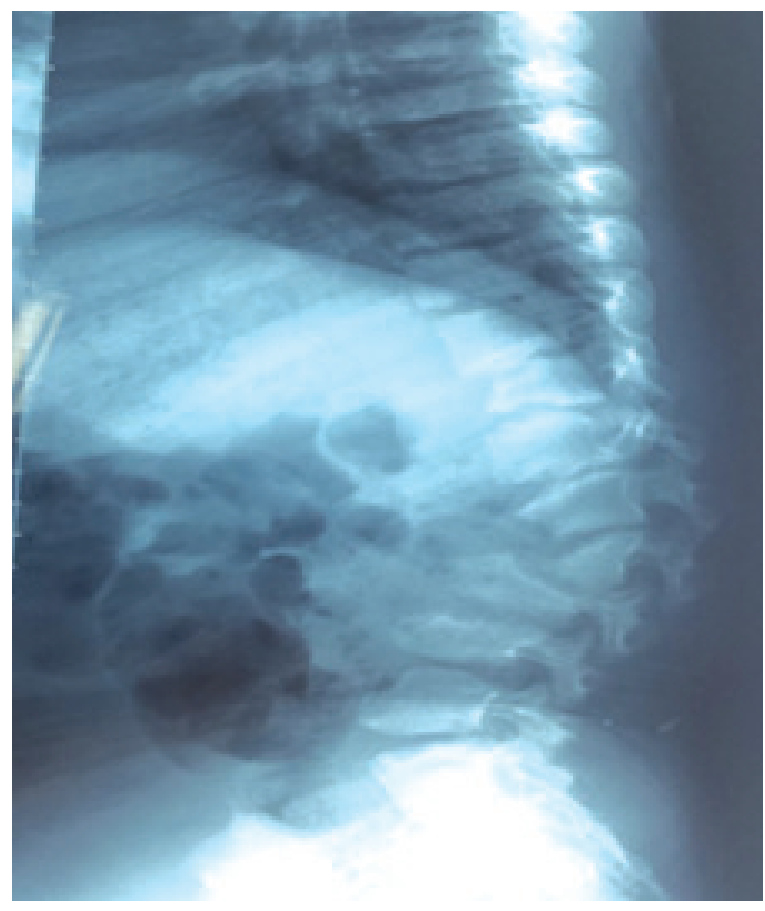

Figure 1 Lateral spine radiograph showed platyspondyly (flat vertebral bodies). Central beaking was evident in $\mathrm{D}_{11}, \mathrm{~L}_{2 \& 3}$ vertebrae. $\mathrm{D}_{11} \& \mathrm{~L}_{2}$ were hypoplastic \& displaced posteriorly forming focal kyphosis.

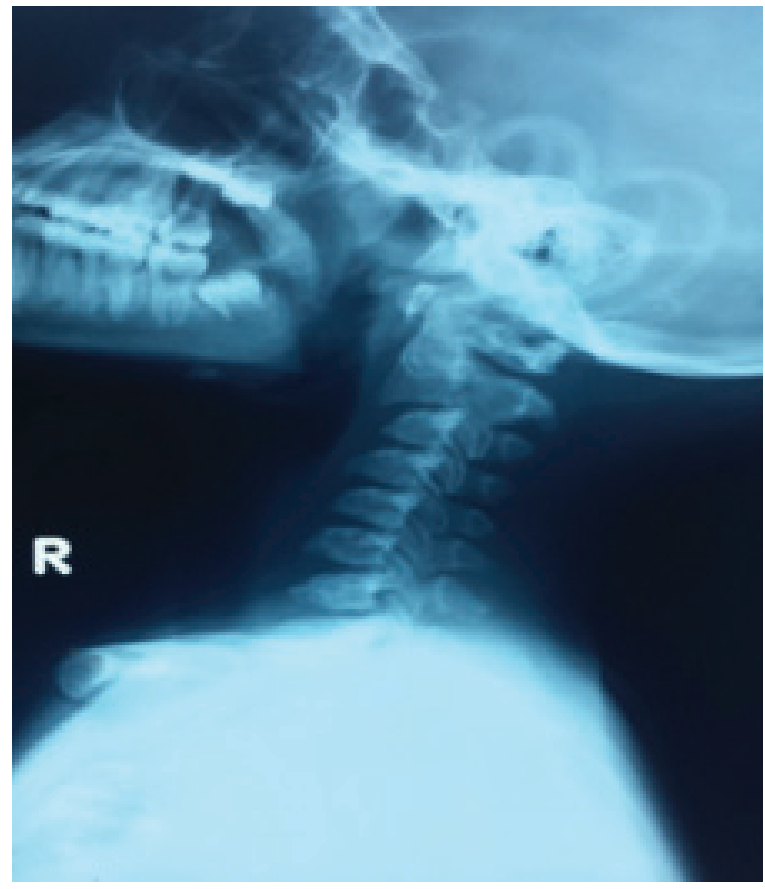

Figure $2 \mathrm{X}$-ray Cervical spine showed flattened vertebra with central beaking. Hypoplastic $\mathrm{C}_{3}$ that displaced posteriorly 


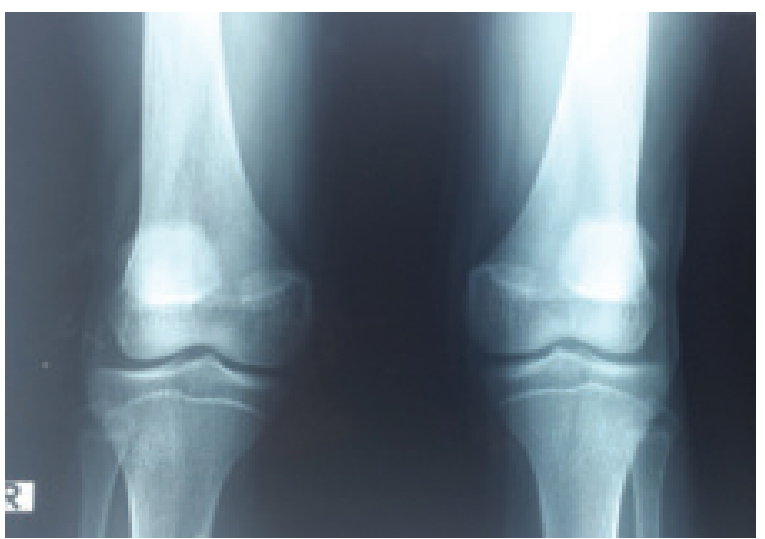

Figure $3 \mathrm{X}$ ray both knee joints A/P view showed mild genu valgus deformity.

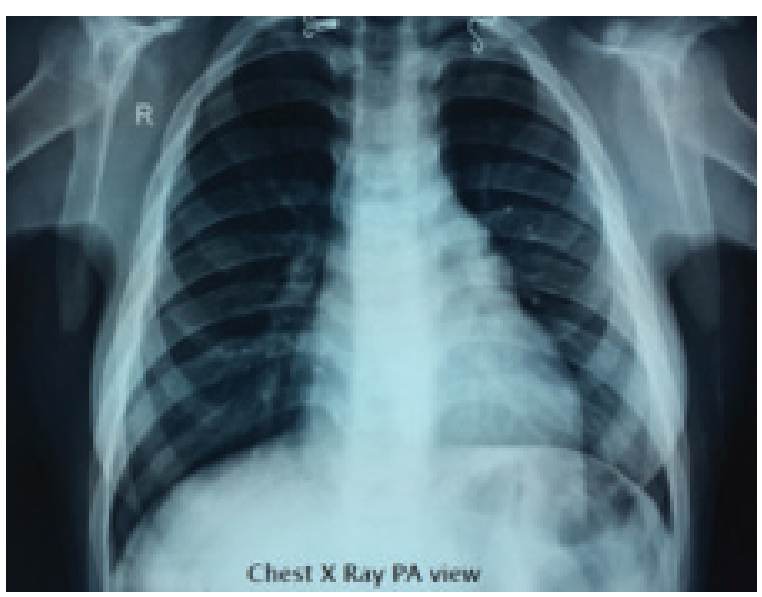

Figure 4 Chest $\mathrm{X}$ ray $\mathrm{P} / \mathrm{A}$ view showed widened ribs and narrow intercostal space.

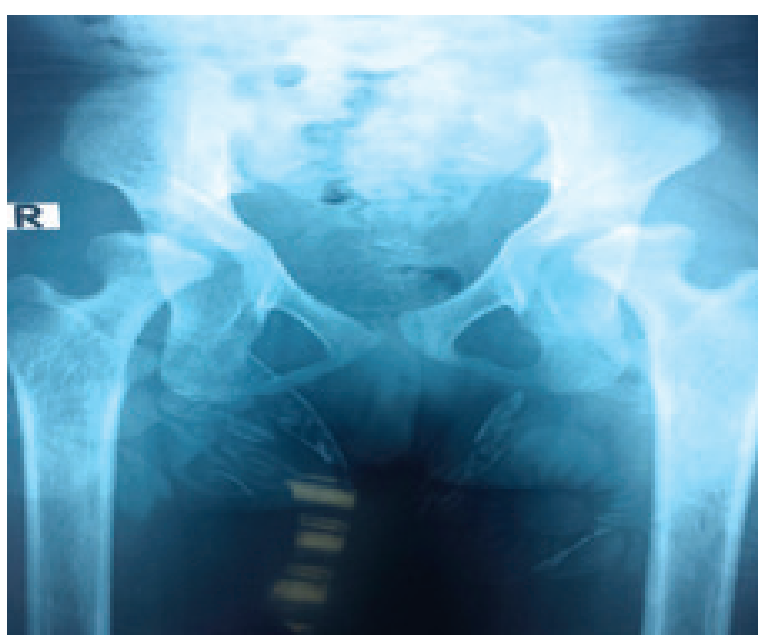

Figure 5 Anteroposterior pelvis radiograph showed maldeveloped, deformed femoral heads with dislocation. Shallow and dysplastic acetabulae with widened symphysis were also noted.
Finally, the patient was diagnosed as Morquios syndrome on the basis of clinical, radiological and positive urinary keratan sulfate level. We treated the patient conservatively with NSAIDS (Nonsteroidal antiinflammatory drugs) and vitamin D supplement. Enzyme replacement was not given as we could not do enzymatic assay and this sort of treatment is not available in our country.

\section{Discussion}

Diagnosis of Morquio syndrome is usually made by characteristic clinical feature, radiological findings, positive urinary mucopolysaccharide and confirmed by definite enzyme assay. Our patient had characteristic clinical features in addition to typical radiological features of Morquio syndrome with positive urinary mucopolysaccharide level. Enzyme test was not done as this investigation is not available in Bangladesh.

We did not find any previously published case report for this condition in our country. Few cases were reported in India and the clinical features were almost identical with our case, though some of the cases from India showed sibling involvement, our patient had a brother who was completely normal. ${ }^{5,6}$

Our Patient had several skeletal changes consistent with Morquio syndrome. The syndrome is characterized by several skeletal changes, which include short stature, microcephaly, short neck, cervical scoliosis, cervical spine subluxation with a very short torso, thoracolumbar kypho-scoliosis, hypoplasia of the odontoid process, a prominent curvature of the spine (scoliosis or kyphosis), flat bridged nose, bulging forehead, barrel chest with pectus carinatum, pot belly, genu valgum and hypermobile joints. ${ }^{7}$ Extra skeletal manifestations include aortic valve disease which was evident in our case clinically and later proved by echocardiograph. Patient can also have mild hepatosplenomegaly, corneal clouding, coarse facial features, prognathism and dental abnormalities. Our patient had dental decay which is common for the syndrome. ${ }^{8,9}$ The airway issues of these patients are frequently complicated by narrow and flat trachea, chronic respiratory disease, recurrent pulmonary infection, obstructive sleep apnoea leading to restrictive lung disease. Ophthalmologiclly such patients manifest slight cloudiness of cornea. The corneal involvement has little effect on vision. Other features are inguinal hernia and loss of nerve function below neck due to cervical myelopathy. ${ }^{10,11}$ 
This syndrome may become complicated by atlantoaxial instability, compression of cervical spinal cord, complications during endotracheal intubation and restrictive lung disease. Characteristic radiological findings include odontoid hypoplasia, hypoplastic lumbar vertebra which may give rise to lumbar kyphosis, platyspondyly of vertebra with central beaking, flaring of ileum, shallow acetabulum, flattening and irregular femoral head with subluxation, coxa and genu valga deformity. ${ }^{12}$ Historically type IV-A was considered to have more severe manifestations than type IV-B. Life expectancy for patients with the type IV-A is normally less than 30 years, but isolated cases of long survival has been documented. ${ }^{13}$ These patients survive into adult life, possibly because they developed ossification of the odontoid peg and $\mathrm{C} 1$ ring to a variable extent. ${ }^{14}$ The diagnosis is usually made on the physical and radiological features of bones, blood enzymes and excessive urinary levels of keratin sulfate which we found to be positive in our case. Once diagnosed it requires a multidisciplinary approach to patient care. ${ }^{15}$ Enzyme replacement therapy (ERT) by elosulfase, $2 \mathrm{mg} /$ $\mathrm{Kg}$ body weight weekly for 6-72 weeks shows some improvement in 3 minute stair climb test and recommended for therapeutic use. ${ }^{16}$

\section{Conclusion}

The typical clinical presentation of Morquio syndrome makes the diagnosis easier for this rare condition. Patient can present to physicians of different specialties starting from Dentist, ENT specialist to Internist and respiratory physicians. Treatment is multi-disciplinary and challenging. Enzyme assay is necessary for confirmation and to detect its type which will help in offering enzyme replacement therapy to the sufferer. Respiratory complications are most common cause of mortality and should be sorted in every cases for early intervention.

Conflict of interest: Nothing to declare.

\section{References}

1. Koto A, Horwitz AL, Suzuki K, Tiffany CW, Suzuki K. The morquio syndrome: Neuropathology and biochemistry. Annals of Neurology: Ann Neurol 1978;4:26-36.

2. Nelson J. Incidence of the mucopolysaccharidoses in Northern Ireland. Human genetics 1997;101:355-58.

3. Morquio L. Sur une forme de dystrophie osseuse familiale. Bull Soc Pediatr Paris 1929;27:145-52.
4. Brailsford JF. Chondro-osteo-dystrophy. Am J Surg 1929;7:404-09.

5. Rekka P, Rathna PV, Jagadeesh S, Seshadri S. Mucopolysaccharidoses type IV A (Morquio syndrome): A case series of three siblings. J Indian Soc Pedod Prev Dent 2012;30:66

6. Sheth JJ, Sheth FJ, Bhattacharya R. Morquio-B syndrome (MPS-IV B) associated with â-galactosidase deficiency in two siblings. Indian J Pediatr 2002;69(1):109-11.

7. Resnick D. Osteochondrodysplasias, dysostoses, chromosomal aberration mucopolysaccharidoses, mucolipidoses and other skeletal dysplasias. Diagnosis of bone and Joint Disorders 1988;5:3501-7.

8. Kinirons MJ, Nelson J. Dental findings in mucopolysaccharidosis type IV A(Morquio's disease type A). Oral Surgery, Oral Medicine, Oral Pathology and Oral Radiology 1990;70:176-79.

9. Levin LS, Jorgenson RJ, Salinas CF. Oral findings in the Morquio syndrome (mucopolysaccharidosis IV). Oral Surgery, Oral Medicine, Oral Pathology 1975;39:390-95.

10. von Noorden GK, Zellweger H, Ponseti IV. Ocular findings in Morquio-Ullrich's disease: with report of two cases. Archives of Ophthalmology 1960;64:585-91.

11. Ghosh M, McCulloch C. The Morquio syndrome-light and electron microscopic findings from two corneas. Canadian journal of ophthalmology. Journal canadien d'ophtalmologie 1974;9:445

12. Langer Jr Lo, Carey LS. The roentgenographic features of the KS mucopolysaccharidosis of Morquio (MorquioBrailsford's disease). Am J Roentgenol 1966;97:1-20.

13. Prat C, Lemaire O, Bret J, Zabraniecki L, Fournié B. Morquio syndrome: diagnosis in an adult. Joint Bone Spine 2008;75:495-8.

14. Ransford AO, Crockard HA, Stevens JM, Modaghegh S. Occipito-atlanto-axial fusion in Morquio-Brailsford syndrome: a ten-year experience. The Journal of Bone and Joint Surgery. British Volume 1996;78:307-13.

15. Montaño AM, Tomatsu S, Gottesman GS, Smith M, Orii T. International Morquio A Registry: clinical manifestation and natural course of Morquio A disease. Journal of Inherited Metabolic Disease 2007;30:165-74.

16. Hiramatsu M, Nakamura K. Elosulfase alfa enzyme replacement therapy attenuates disease progression in a nonambulatory Japanese patient with Morquio A syndrome (case report). Molecular Genetics and Metabolism Reports 2017;13:76-79. 